Short report

\title{
Ilex paraguariensis supplementation may be an effective nutritional approach to modulate oxidative stress during perimenopause
}

\author{
Ariana Aparecida Ferreira Pereira ${ }^{\mathrm{a}, \mathrm{b}, 1}$, Keny Gonçalves Tirapeli ${ }^{\mathrm{a}, \mathrm{b}, 1}$, Antonio Hernandes Chaves-Neto ${ }^{\mathrm{b}}$, \\ Matheus da Silva Brasilino ${ }^{b}$, Cláudia Quintino da Rocha ${ }^{c}$, Adriane Belló-Klein ${ }^{\mathrm{d}}$, Suzana Francisca Llesuy ${ }^{\mathrm{e}}$, \\ Rita Cássia Menegati Dornelles ${ }^{a}$, Ana Cláudia de Melo Stevanato Nakamune ${ }^{\mathrm{a}, \mathrm{b}, *}$
}

a Programa Multicêntrico de Pós-Graduação em Ciências Fisiológicas, SBFis/UNESP, Univ Estadual Paulista, Araçatuba, São Paulo, Brazil

${ }^{\mathrm{b}}$ Laboratory of Biochemistry, Department of Basic Sciences, Araçatuba Dental School, UNESP - Univ Estadual Paulista, Araçatuba, São Paulo, Brazil

c Department of Organic Chemistry, Chemistry Institute, UNESP - Univ Estadual Paulista, Araraquara, São Paulo, Brazil

d Department of Physiology, Institute of Basic Health Sciences, Federal University of Rio Grande do Sul, Porto Alegre, Rio Grande do Sul, Brazil

e Department of Analytical Chemistry and Physical Chemistry, School of Pharmacy and Biochemistry, University of Buenos Aires, Buenos Aires, Argentina

\section{A R T I C L E I N F O}

\section{Article history:}

Received 12 June 2016

Received in revised form 8 December 2016

Accepted 13 January 2017

Available online 14 January 2017

Section Editor: Holly M. Brown-Borg

\section{Keywords:}

Mate

Perimenopause

Antioxidant capacity

Oxidative stress

Oxidative damage

\begin{abstract}
A B S T R A C T
Perimenopause is a period in a woman's life that precedes menopause and is characterized by hormonal changes that result in increased oxidative stress. Since oxidative stress is associated with age-related diseases and perimenopausal symptoms including somato-vegetative manifestations, nutritional antioxidant supplementation may be an effective approach to minimizing this stress. Mate tea (MT) (Ilex paraguariensis), a typical and inexpensive beverage consumed in the Brazilian south-east, Argentina and Uruguay, increases antioxidant defense. We hypothesized that MT could minimize oxidative stress during perimenopause by modulating enzymatic antioxidant defense. To test this, we analyzed the lipid oxidative damage and antioxidant defense in erythrocytes and liver of rats, after MT treatment. Female Wistar rats (aged 16 months) in proven perimenopause period received $20 \mathrm{mg} / \mathrm{kg} \mathrm{BW} /$ day of mate tea, by gavage (PM + MT group) or water (PM group). Female rats aged 4 months (AD group) received water. Erythrocytes and liver were used to determine lipid oxidative damage, determined by malondialdehyde (MDA); superoxide dismutase (SOD), glutathione peroxidase (GPx) and catalase (CAT) activities. Total plasma antioxidant capacity was examined by ferric reducing antioxidant power assay (FRAP) and estrogen by radioimmunoassay. MT increased FRAP and did not change estrogen levels. Increased SOD and GPx, and reduced MDA were observed in both tissues studied. Increased CAT activity was observed only in the liver. We confirmed the hypothesis that MT was capable of minimizing oxidative stress in this period of life by modulating antioxidant defense.
\end{abstract}

(c) 2017 Elsevier Inc. All rights reserved.

\section{Introduction}

Perimenopause is a period in a woman's life, characterized by physiological changes associated with the end of reproductive capacity, terminating completely with menopause (Zitňanová et al., 2011). This transition period is marked by wide fluctuation in estrogen levels from month to month, preceding the decline in postmenopause (Kermath and Gore, 2012). Hormonal changes during perimenopause are associated with increased oxidative stress, manifested by elevated lipid oxidative damage (Zitňanová et al., 2011). Since oxidative stress is associated with age-related diseases, such as osteoporosis, atherosclerosis, cancer, endothelial dysfunction (Zitňanová et al., 2011), chronic

\footnotetext{
* Corresponding author at: Department of Basic Sciences, Building 31, UNESP, Rodovia Marechal Rondon Km 527, 16018-805 Araçatuba, São Paulo, Brazil.

E-mail address: anacmsn@foa.unesp.br (A.C.M.S. Nakamune).

1 These authors contributed equally to this work.
}

liver diseases (Brady, 2015), and somato-vegetative manifestations such as hot flashes, night sweats, heart palpitation and sleep disturbance (Zitňanová et al., 2011), nutritional antioxidant supplementation may be an effective approach to treating woman during perimenopause and thus in postmenopause.

In the Brazilian population's diet, mate tea (MT) is one of the largest contributors to antioxidant capacity (Torres and Farah, 2016). This is a typical and inexpensive beverage consumed in the Brazilian Southeast, Argentina, and Uruguay, prepared by the infusion of Ilex paraguariensis (Heck and de Mejia, 2007). Regular and prolonged consumption of MT by healthy young women may decrease lipid peroxidation and increase the gene expression of antioxidant enzymes superoxide dismutase (SOD), catalase (CAT) and glutathione peroxidase (GPx) (Matsumoto et al., 2009), however its effect has not yet been evaluated in perimenopausal women. Postmenopausal use of MT has been shown to enhance bone mineral density, by a mechanism not yet fully elucidated (Conforti et al., 2012). 
Erythrocytes have been intensely investigated to understand oxidative stress and study possible interventions to reduce the damage it causes, because of continuous exposure to high concentrations of oxygen and oxygen reactive species (Pandey and Rizvi, 2010). The effects of changes in enzymatic antioxidant defense and increase in oxidative stress on erythrocytes have previously been demonstrated during perimenopause (Sánchez-Rodríguez et al., 2012). The liver is another tissue very susceptible to oxidative stress, as result of reactive oxygen species produced in energy metabolism and during the detoxification process (Giergiel et al., 2012). The liver has been shown to undergo a decrease in antioxidant defense, as a result of aging and postmenopause (Giergiel et al., 2012), however, the effect of perimenopause on liver antioxidant defense systems has yet not been well defined; and up to now, the MT effect on this period of life has not been investigated.

In this context, the authors proposed the present study. We hypothesized that MT could minimize oxidative stress during perimenopause by modulating antioxidant defense. To test this, we analyzed the lipid oxidative damage and antioxidant defense in rats during perimenopause, after eight weeks of MT treatment.

\section{Materials and methods}

\subsection{Mate tea}

MT was prepared using instant powder (Leão Jr. ${ }^{\circledR}$, Curitiba, PR, Brazil), batch 7891098000088 , in pure water $(0.05 \mathrm{~g} / \mathrm{mL})$ at room temperature. Total polyphenol was determinate by the Folin-Ciocalteu method (Singleton et al., 1999), using gallic acid as a standard. Total antioxidant capacity was evaluated by the ferric reducing antioxidant potential (FRAP assay), as previously described (Benzie and Strain, 1996). A series of $\mathrm{Fe}_{2} \mathrm{SO}_{4}$ solutions were used for calibration. The reducing power was expressed in $\mathrm{Fe}^{2+}$ antioxidant capacity per $\mathrm{g}$ MT powder. MT was also analyzed by electrospray ionization (ESI) and multistage fragmentation performed in an interface-type ion-trap (IT). The negative mode was chosen. For generation and analysis of first-order mass spectra (MS) and for the remaining experiments in multiple stages (MSn), the following parameters were followed: capillary voltage of $-4 \mathrm{~V}$, spray voltage of $-5 \mathrm{kV}$, capillary temperature $280^{\circ} \mathrm{C}$, carrier gas $\left(\mathrm{N}_{2}\right)$ flow 60 (random units). The track acquisition was $\mathrm{m} / \mathrm{z} 150$ 1500 , with two or more events performed simultaneously. The first event was a full scan spectrum of masses to collect data on ions in the range $m / z$ established. The remaining events were MSn experiments conducted from data for the first scan pre-selected precursor ions with collision energy between 20 and 30\% of the total energy of the instrument. The Xcalibur (Thermo Scientific ${ }^{\circledR}$ ) software was used for collection and processing the spectral data.

\subsection{Animals}

The local Ethics Committee on Research Involving Animals of the "Universidade Estadual Paulista/UNESP" approved all procedures performed in this study (Permission Number: 00517-2012). Female Wistar rats aged 4 months (Adult group - $\mathrm{AD}$ ), and 16 months, were housed in a sanitary and controlled room $\left(22 \pm 2{ }^{\circ} \mathrm{C} ; 12 / 12 \mathrm{~h}\right.$ light/dark cycle; lights on at 7:00 h; $55 \pm 10 \%$ of relative humidity) with free access to feed and water. After the acclimation period (15 days) aged rats were randomly subdivided into Group PM (perimenopause) and Group $\mathrm{PM}+$ MT. The animals of Group PM + MT received $20 \mathrm{mg} / \mathrm{kg}$ BW/day of MT, by gavage $(0.5 \mathrm{~mL})$; Groups $\mathrm{AD}$ and $\mathrm{PM}$ received an equal volume of water. The treatment period was eight weeks. Before and during the treatment, the stages and duration of the estrous cycle were monitored daily by microscopic examination of vaginal smears (Chen et al., 2013). Only adult females with a normal estrous cycle (four or five days) were used. Only aged rats with cycles of six or more days, characterizing periestropause, remained in the Group PM or Group PM + MT (Chen et al., 2013). The final number of animals was 10/group. Periestropause resembles perimenopause in women (Kermath and Gore, 2012; Chen et al., 2013). Body mass was followed-up weekly, and water and feed consumption, daily. To avoid variation in antioxidant intake, the same batch of standard rodent chow (Purina-Labina ${ }^{\circledR}$, Brazil) was used right from the acclimation period through to the end of the experiment.

\subsection{Sample acquisition}

Blood was obtained after an overnight fast; by means of cardiac puncture, after anesthesia with sodium pentobarbital (50 mg/kg BW). Blood $(5.0 \mathrm{~mL})$ was transferred to heparinized tubes, centrifuged at $1000 \times \mathrm{g}$ at $4{ }^{\circ} \mathrm{C}$ for $15 \mathrm{~min}$. Plasma was removed and frozen at $-80^{\circ} \mathrm{C}$. Erythrocytes were washed three times with $\mathrm{NaCl} 0.9 \%$ (v/v). Aliquots were stored at $-80^{\circ} \mathrm{C}$ in $\mathrm{HCl} 1 \mathrm{mmol} / \mathrm{L}$ and $\mathrm{MgSO}_{4} 4 \mathrm{mmol} / \mathrm{L}$, diluted $1: 100(\mathrm{v} / \mathrm{v})$ for later enzymatic antioxidant activity analysis. The liver was removed immediately after the animals were sacrificed, transferred to liquid nitrogen and frozen at $-80^{\circ} \mathrm{C}$. Immediately before the analysis, the liver was homogenized $(100 \mathrm{mmol} / \mathrm{L}$ Tris- $\mathrm{HCl}, 50 \mathrm{mmol} / \mathrm{L}$ EDTA; pH 7.0, 10\% w/v) using a Potter-Elvehjem glass homogenizer (2600 rpm during $40 \mathrm{~s}$ ) and centrifuged $\left(1000 \times \mathrm{g}\right.$, at $\left.4{ }^{\circ} \mathrm{C}, 10 \mathrm{~min}\right)$ to obtain the supernatant.

\subsection{Estrogen assay}

Estrogen in plasma was determined by radioimmunoassay using a commercial kit, MP Biomedicals LLC (Diagnostics Divisions, New York, USA).

\subsection{Oxidative stress parameters}

Plasma total antioxidant capacity was measured by FRAP assay (Benzie and Strain, 1996) that offers an antioxidant activity index (AAI) or reduction potential values for the different biological fluids. A standard ferrous sulphate curve was used.

Lipid peroxidation was measuring in erythrocyte and liver tissue homogenates, by analyzing the amount of malondialdehyde (MDA), a thiobarbituric acid reactive substance, as previously described (Buege and Aust, 1978), using an extinction of coefficient of $1.56 \times 10^{5} \mathrm{M}^{-1} \mathrm{~cm}^{-1}$. Protein was quantified based on Lowry's method, using bovine serum albumin as standard.

Antioxidant enzymes were measured in erythrocyte and liver tissue homogenates. Superoxide dismutase (SOD) activity was evaluated, based on superoxide radical reaction inhibition with pyrogallol; and the absorbance values were measured at $420 \mathrm{~nm}$ (Araújo et al., 2006). Glutathione peroxidase (GPx) activity was measured by following $\beta$ nicotinamide adenine dinucleotide phosphate (NADPH) oxidation at $340 \mathrm{~nm}$ (Araújo et al., 2006). Catalase (CAT) activity was evaluated by following the decrease in hydrogen peroxide levels (Araújo et al., 2006).

\subsection{Statistical analysis}

All data, presented as the mean \pm standard error of the mean (SEM), showed normal distribution (Kolmogorov-Smirnov test). Comparisons between two groups were made using the Student's-t-test. All analysis was performed using GraphPad Prism 6 program (La Jolla, CA, USA). A value of $p<0.05$ was considered significant.

\section{Results and discussion}

\subsection{Mate tea}

Total antioxidant capacity of MT was $534.67 \mathrm{Fe}^{2+}$ antioxidant capacity/g MT powder. Total polyphenol concentration $(113.37 \pm 0.34 \mathrm{mg}$ of gallic acid per $g$ powder) was higher in another study (Matsumoto et al., 2009); however the standard used was different. The biological properties of MT resulted from synergism among its caffeine and other 
phenolic compounds, either modified or not during the absorption process (Matsumoto et al., 2009). Mass spectrometry confirmed the presence cis-3-O-caffeoylquinic acid, 5-O-p-cumaroilquinic acid, 3-Oferuloylquinic acid and 4,5-di-O-caffeoylquinic acid (Fig. 1), phenolic compounds associated with antioxidant activity and some pharmacological properties attributed to MT (Heck and de Mejia, 2007; Bastos et al., 2007).

\subsection{Validation of experimental groups}

This study involved adult female Wistar rats with a regular estrous cycle and aged rats during perimenopause, either treated with MT, or not. Analysis of the estrous cycle (Table 1) of Group PM, exhibited a longer period, compatible with perimenopause (Kermath and Gore, 2012; Chen et al., 2013). The changes in the estrous cycle of Group PM were accompanied by reduction in estrogen, as expected (Kermath and Gore, 2012), but MT did not change this parameter. A normal cycle was confirmed in the adult group (Table 1). Feed intake, water consumption and body weight were not changed by MT (data not shown), indicating that changes in oxidative stress markers were associated with perimenopause instead of with variations in calorie intake or body mass reduction promoted by MT treatment.

\subsection{Plasma antioxidant defense}

The authors used dose $(20 \mathrm{mg} / \mathrm{kg} \mathrm{BW})$ and experimental period (eight weeks) according to a pilot study, and increased 83.5\% FRAP in Group PM + MT (Table 1). Matsumoto et al. (2009) also found increased antioxidant activity in plasma of healthy young women after MT, however using a dose far above that which we used ( $5 \mathrm{~g} / 500 \mathrm{~mL} /$ day). Group PM showed a $19.1 \%$ increase in plasma antioxidant, compared with Group AD (Table 1), as has previously been observed in women during perimenopause (Zitňanová et al., 2011) and in post-menopause (Ramírez-Expósito et al., 2014). Plasma antioxidant capacity is a function of the individual and synergistic effects of numerous components such as uric acid, ascorbic acid, tocopherols, bilirubin, and albumin, among others (Boaventura et al., 2012). According to Zitňanová et al. (2011) and Ramírez-Expósito et al. (2014), the FRAP increase in Group PM might
Table 1

Estrous cycle and plasma parameters in adults, perimenopause and perimenopause groups treated with MT.

\begin{tabular}{lccc}
\hline & AD & PM & PM + MT \\
\hline Estrous cycle (days) & $3.90 \pm 0.21$ & $7.50 \pm 0.47^{\mathrm{a}}$ & $7.60 \pm 0.40$ \\
Estrogen $(\mathrm{pg} / \mathrm{mL})$ & $540.7 \pm 83.26$ & $176.6 \pm 21.15^{\mathrm{a}}$ & $224.2 \pm 61.99$ \\
FRAP $\left(\mathrm{mmol} \mathrm{Fe}{ }^{2+} / \mathrm{L}\right)$ & $2.19 \pm 0.08$ & $2.61 \pm 0.09^{\mathrm{a}}$ & $4.02 \pm 0.11^{\mathrm{b}}$ \\
\hline
\end{tabular}

Data show the mean \pm SEM. $(n=10)$.

Student's-t-test.

a $p<0.05$ PM vs. AD group.

b $p<0.05$ PM + MT vs. PM group.

have resulted from changes in one or more of these components, as an adaptive response to the increased levels of oxidative stress in this period of life.

\subsection{Oxidative stress parameters on erythrocytes}

MT modulated the enzymatic antioxidant defense and reduced oxidative damage in erythrocytes (Table 2). Enzymatic antioxidant defense performed by enzymes such as SOD, responsible for the dismutation of superoxide anion in hydrogen peroxide $\left(\mathrm{H}_{2} \mathrm{O}_{2}\right)$, GPx reduced not only $\mathrm{H}_{2} \mathrm{O}_{2}$ but alkyl hydroperoxides, and CAT that removed $\mathrm{H}_{2} \mathrm{O}_{2}$, when the concentration of this species was high (Giergiel et al., 2012). Oxidative stress may be shown by lipid peroxidation products, such MDA (Pandey and Rizvi, 2010). Group PM showed a 33.98\% increase in MDA compared with Group AD, as has been described in the plasma of women during perimenopause (Zitňanová et al., 2011) and postmenopause (Ramírez-Expósito et al., 2014; Sánchez-Rodríguez et al., 2012). In Group PM, the increase in MDA might have resulted from the $71.4 \%$ decrease in SOD compared with Group AD (Table 2). There was also a 69.47\% decrease in GPx. Similar results have been observed in the serum (Ramírez-Expósito et al., 2014) and erythrocytes (SánchezRodríguez et al., 2012) of women in menopause. This decrease in SOD and GPx was related to downregulation of these enzymes, consequently reducing estrogen levels (Ramírez-Expósito et al., 2014), as we also observed in our study. An $81.85 \%$ reduction in CAT was verified in the erythrocytes of Group PM, corroborating the findings of Ogunro et al.

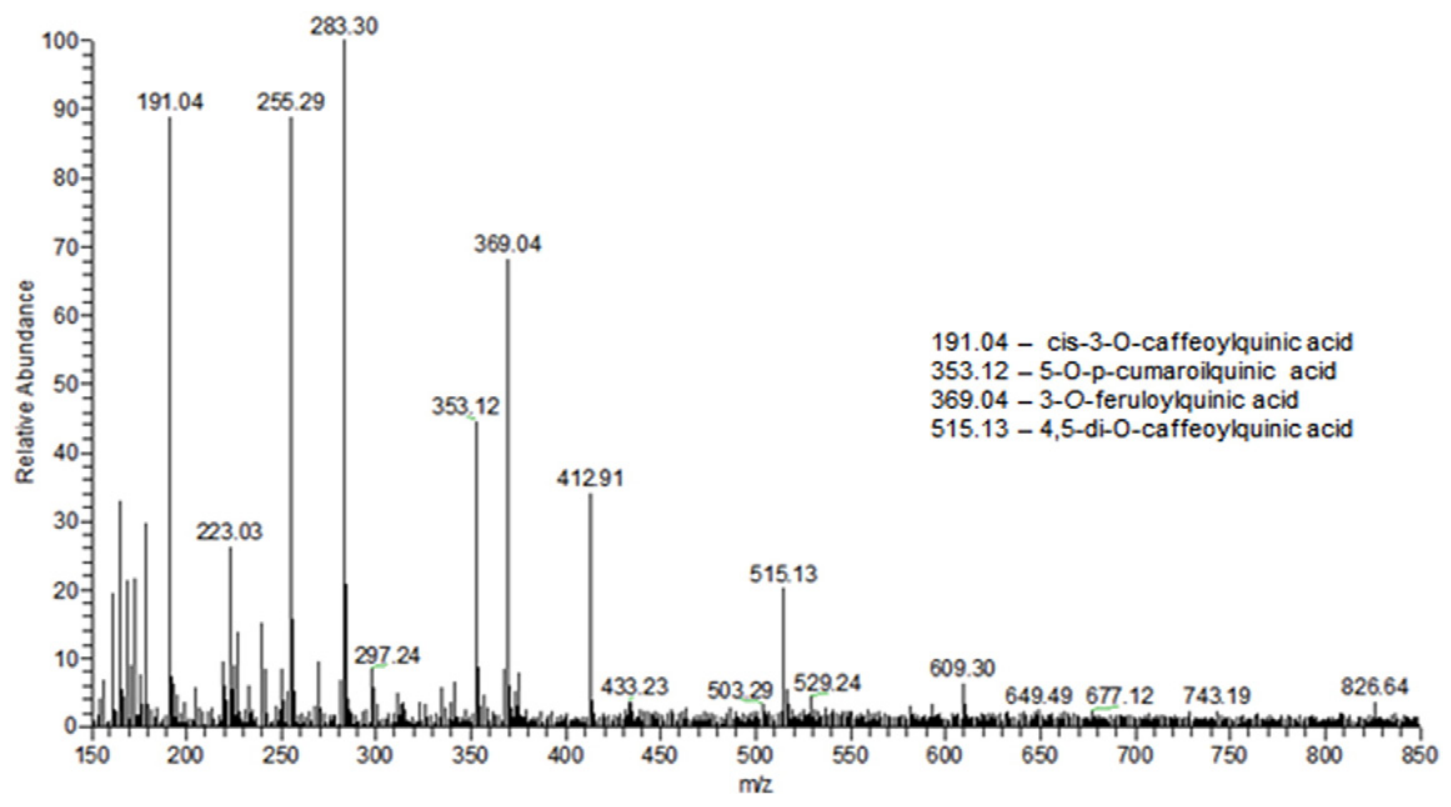

Fig. 1. Mass spectrum of mate tea (FIA-ESI-IT-MSn - negative mode). 
Table 2

MDA and antioxidant enzymes in erythrocytes and liver of adult, perimenopause and perimenopause groups treated with MT.

\begin{tabular}{|c|c|c|c|c|c|c|}
\hline & \multicolumn{3}{|l|}{ Erythrocytes } & \multicolumn{3}{|l|}{ Liver } \\
\hline & $\mathrm{AD}$ & PM & $\mathrm{PM}+\mathrm{MT}$ & $A D$ & PM & $\mathrm{PM}+\mathrm{MT}$ \\
\hline MDA & $50.9 \pm 4.21$ & $68.2 \pm 4.64^{\mathrm{a}}$ & $14.6 \pm 3.54^{\mathrm{b}}$ & $191.2 \pm 11.13$ & $175.2 \pm 7.52$ & $144.7 \pm 2.49^{b}$ \\
\hline SOD & $0.42 \pm 0.06$ & $0.12 \pm 0.01^{\mathrm{a}}$ & $0.84 \pm 0.12^{\mathrm{b}}$ & $1.59 \pm 0.15$ & $2.09 \pm 0.08^{a}$ & $2.65 \pm 0.12^{\mathrm{b}}$ \\
\hline GPx & $210.0 \pm 11.47$ & $64.10 \pm 11.86^{\mathrm{a}}$ & $888.3 \pm 131.8^{\mathrm{b}}$ & $112.7 \pm 9.03$ & $26.22 \pm 3.90^{\mathrm{a}}$ & $56.62 \pm 6.41^{\mathrm{b}}$ \\
\hline CAT & $2.48 \pm 0.31$ & $0.45 \pm 0.10^{\mathrm{a}}$ & $0.42 \pm 0.04$ & $0.035 \pm 0.004$ & $0.071 \pm 0.008^{\mathrm{a}}$ & $0.103 \pm 0.005^{b}$ \\
\hline
\end{tabular}

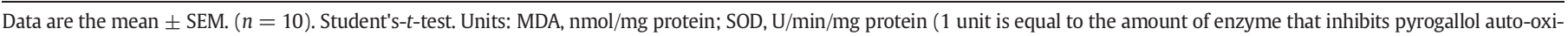
dation by 50\%); GPx, mmol of GSH consumed/min/mg protein; CAT, nmol of $\mathrm{H}_{2} \mathrm{O}_{2}$ consumed/min/mg protein.

a $p<0.05$ Group PM vs. Group AD.

b $p<0.05$ Group PM + MT vs. Group PM.

(2014), despite the absence of changes that were observed by RamírezExpósito et al. (2014), in the serum of women in postmenopause.

\subsection{Oxidative stress parameters on liver}

MT capacity for increasing enzymatic antioxidant defense was also observed in liver homogenate, although there was no increase in oxidative damage. Differently from the erythrocytes, there was no higher MDA in liver homogenate of Group PM compared with Group AD (Table 2). MDA could be indicative of oxidative stress (Pandey and Rizvi, 2010), which may result from the decrease in the antioxidant ability of the system. Whereas, in liver homogenate of Group PM, increases in SOD and CAT activity were observed, and these may have contributed to no changes in MDA (Table 2). Significant increase in MDA and CAT activity and an insignificant increase in SOD activity have been observed in liver of female rats with surgically-induced menopause (Ozgönül et al., 2003). Our article is the first to report increase (31.44\%) in SOD activity and CAT boost (136.6\%) in rat livers also during perimenopause (Table 2), before increase in MDA. The increase in CAT activity pointed out the development of a mechanism of reactive oxygen species tolerance in cases with reduced GPx, which have been described in the serum of women in menopause (Ramírez-Expósito et al., 2014) and by our study, in rat erythrocytes. GPx activity was reduced in the liver of Group PM (76.70\%) compared with Group AD (Table 2). Enhanced SOD, CAT and GPx activity was observed after MT, as Matsumoto et al. (2009) also observed in leukocytes, and we observed in erythrocytes.

Our results confirm the difference in tissue sensitivity to oxidative stress related to antioxidant enzymatic defense mechanism variations in rats during perimenopause, previously described in other tissues in postmenopause and aging individuals (Giergiel et al., 2012) and confirmed the hypothesized that MT was capable of minimizing oxidative damage in this period of life, by modulating antioxidant defense.

For the present time, our study was limited to assessing MDA, since some studies have reported that consumption of MT decreased lipid oxidative damage (Matsumoto et al., 2009; Boaventura et al., 2012); and that estrogen depletion or postmenopause in women elevated lipid peroxidation (Giergiel et al., 2012). Protein, carbohydrate and nucleic acid oxidative damage were not investigated, as the reactive oxygen species involved in the process were not quantified. Our work was limited to studying soluble MT, but it would be interesting to conduct further studies to evaluate the influence of the bioactive compounds found, on the most relevant effects, although it has been reported that the benefits of MT depend on the synergism among its bioactive compounds (Matsumoto et al., 2009).

\section{Conclusion}

MT supplementation may be an inexpensive but effective nutritional approach to reducing oxidative damage during perimenopause. New investigations are being conducted by our group to investigate MT effect on other tissues during this period of life.

\section{Disclosures}

There are no conflicts of interest that need to be disclosed by any author.

\section{Acknowledgments}

The authors thank the Universidade Estadual Paulista "Júlio de Mesquita Filho" (UNESP), the "Coordenação de Aperfeiçoamento de Pessoal de Nível Superior" (CAPES), for supporting the present study. We would also like to thank Dr. Wagner Villegas (Department of Organic Chemistry, Chemistry Institute, Universidade Estadual Paulista "Júlio de Mesquita Filho" (UNESP), Araraquara, SP, Brazil), for carrying out the chromatographic and MS analysis.

\section{References}

Araújo, A.S., Ribeiro, M.F., Enzveiler, A., Schenkel, P., Fernandes, T.R., Partata, W.A. Irigoyen, M.C., Llesuy, S., Belló-Klein, A., 2006. Myocardial antioxidant enzyme activities and concentration and glutathione metabolism in experimental hyperthyroidism. Mol. Cell. Endocrinol. 249, 133-139.

Bastos, D.H., Saldanha, L.A., Catharino, R.R., Sawaya, A.C., Cunha, I.B., Carvalho, P.O., Eberlin, M.N., 2007. Phenolic antioxidants identified by ESI-MS from Yerba mate (Ilex paraguariensis) and green tea (Camelia sinensis) extracts. Molecules 12 (3), 423-432.

Benzie, I.F., Strain, J.J., 1996. The ferric reducing ability of plasma (FRAP) as a measure of 'antioxidant power': the FRAP assay. Anal. Biochem. 239, 70-76.

Boaventura, B.C., Di Pietro, P.F., Stefanuto, A., Klein, G.A., de Morais, E.C., de Andrade, F., Wazlawik, E., da Silva, E.L., 2012. Association of mate tea (Ilex paraguariensis) intake and dietary intervention and effects on oxidative stress biomarkers of dyslipidemic subjects. Nutrition 28 (6), 657-664.

Brady, C.W., 2015. Liver disease in menopause. World J. Gastroenterol. 21 (25), $7613-7620$

Buege, J.A., Aust, S.D., 1978. Microsomal lipid peroxidation. Methods Enzymol. 52, 302-309.

Chen, S. Asakawa, T., Ding, S., Liao, L., Zhang, L., Shen, J., Yu, J., Sugiyama, K., Namba, H., Li, C., 2013. Chaihu-Shugan-San administration ameliorates perimenopausal anxiety and depression in rats. PLoS One 8 (8), e72428.

Conforti, A.S., Gallo, M.E., Saraví, F.D., 2012. Yerba Mate (Ilex paraguariensis) consumption is associated with higher bone mineral density in postmenopausal women. Bone 50 (1), 9-13.

Giergiel, M., Lopucki, M., Stachowicz, N., Kankofer, M., 2012. The influence of age and gender on antioxidant enzyme activities in humans and laboratory animals. Aging Clin. Exp. Res. 24 (6), 561-569.

Heck, C.I., de Mejia, E.G., 2007. Yerba Mate Tea (Ilex paraguariensis): a comprehensive review on chemistry, health implications, and technological considerations. J. Food Sci. 72 (9), 138-151.

Kermath, B.A., Gore, A.C., 2012. Neuroendocrine control of the transition to reproductive senescence: lessons learned from the female rodent model. Neuroendocrinology 96 (1), 1-12.

Matsumoto, R.L., Bastos, D.H., Mendonça, S., Nunes, V.S., Bartchewsky, W., Ribeiro, M.L., de Oliveira Carvalho, P., 2009. Effects of mate tea (Ilex paraguariensis) ingestion on mRNA expression of antioxidant enzymes, lipid peroxidation and total antioxidant status in healthy young women. J. Agric. Food Chem. 57 (5), 1775-1780.

Ogunro, P.S., Bolarinde, A.A., Owa, O.O., Salawu, A.A., Oshodi, A.A., 2014. Antioxidant status and reproductive hormones in women during reproductive, perimenopausal and postmenopausal phase of life. Afr. J. Med. Med. Sci. 43 (1), 49-57.

Ozgönül, M., Oge, A., Sezer, E.D., Bayraktar, F., Sözmen, E.Y., 2003. The effects of estrogen and raloxifene treatment on antioxidant enzymes in brain and liver of ovarectomized female rats. Endocr. Res. 29 (2), 183-189.

Pandey, K.B., Rizvi, S.I., 2010. Markers of oxidative stress in erythrocytes and plasma during aging in humans. Oxidative Med. Cell. Longev. 3 (1), 2-12.

Ramírez-Expósito, M.J., Sánchez-López, E., Cueto-Ureña, C., Dueñas, B., Carrera-González, P., Navarro-Cecilia, J., Mayas, M.D., Arias de Saavedra, J.M., Sánchez-Agesta, R., 
Martínez-Martos, J.M., 2014. Circulating oxidative stress parameters in pre- and postmenopausal healthy women and in women suffering from breast cancer treated or not with neoadjuvant chemotherapy. Exp. Gerontol. 58, 34-42.

Sánchez-Rodríguez, M.A., Zacarías-Flores, M., Arronte-Rosales, A., Correa-Muñoz, E. Mendoza-Núñez, V.M., 2012. Menopause as risk factor for oxidative stress. Menopause 19 (3), 361-367.

Singleton, V.L., Orthofer, R., Lamuela-Raventós, R.M., 1999. Analysis of total phenols and other oxidation substrates and antioxidants by means of Folin-Ciocalteu reagent. Methods Enzymol. 299, 152-178.
Torres, T., Farah, A., 2016. Coffee, mate, açaí and beans are the main contributors to the antioxidant capacity of Brazilian's diet. Eur. J. Nutr. (Epub ahead of print).

Zitňanová, I., Rakovan, M., Paduchová, Z., Dvořáková, M., Andrezálová, L., Muchová, J., Simko, M., Waczulíková, I., Duračková, Z., 2011. Oxidative stress in women with perimenopausal symptoms. Menopause 18 (11), 1249-1255. 